\title{
The Relationship of Trauma from Occlusion with Chronic Periodontitis Based on the Quality and Quantity of Alveolar Bone in the Radigraphic Features
}

\author{
Dharshini Neelamegan \\ Student \\ Faculty of Dentistry, Universitas Sumatera Utara \\ Medan, Indonesia
}

\author{
Rini Octavia Nasution \\ Department of Periodontology \\ Faculty of Dentistry, Universitas Sumatera Utara \\ Medan, Indonesia
}

\begin{abstract}
Periodontitis has been defined as the presence of gingival inflammation at sites where there has been a pathological detachment of collagen fibers from cementum, the junctional epithelium has migrated apically, and bone loss can be detected radiographically. One of the factors, thought to be responsible for the initiation of inflammatory periodontal disease, is occlusal trauma. The purpose of this study is to find the relationship of trauma from occlusion with chronic periodontitis based on the quality and quantity of alveolar bone in the radiographic features.This study is a descriptive analytical research with cross-sectional approach and the sample is determine by accidental sampling. According to the study, 11 patients were found with total 74 teeth and had been divided to 35 teeth due to trauma from occlusion and 39 teeth with normal occlusion at the Periodontal Clinic, Faculty of Dentistry USU Medan both men and women at the age of 40 to 60 years old. This study begins by filling in the informed concent, clinical examination of the oral cavity and periapical radiographic images in the patient. Data analysis was performed by using a Chi Square test to determine the relationship of trauma from occlusion with chronic periodontitis based on the quality and quantity of alveolar bone in the radiographic features. The result of statistical test shows that there is a significant correlation between trauma from occlusion with periodontal ligament space (mesial) with $\mathbf{p}$ $=0,001(p<0,005)$, lamina dura (mesial) with $p=0,000(p$ $<0,005)$ and pattern of alveolar bone destruction (both mesial and distal) with $p=0,000(p<0,005)$. The statistical test also showed that there is no significant relationship between trauma from occlusion with periodontal ligament space (distal) with $p=0,051$ ( $p<0,005)$, lamina dura (distal) with $p=0,082(p<0,005)$ and loss of bone height with the value $p=0.577(p<0.005)$. The results show that there is an associated relationship of trauma from occlusion with chronic periodontitis based on the quality and quantity of alveolar bone in radiographic features.
\end{abstract}

Keywords-trauma from occlusion, periodontitis, alveolar bone, quality and quantity, radiographic features

\section{INTRODUCTION}

Periodontitis has been defined as the presence of gingival inflammation at sites where there has been a pathological detachment of collagen fibers from cementum, the junctional epithelium has migrated apically, and bone loss can be detected radiographically [1]. The etiology of periodontal disease is multifactorial. One of the factors, thought to be responsible for the initiation of inflammatory periodontal disease, is occlusal trauma [2].

WHO in 1978 defined trauma from occlusion as "damage in the periodontium caused by, stress on the teeth produced directly or indirectly by the teeth of the opposing jaw". Other terms often used are, traumatizing occlusion, occlusal trauma, occlusal overload, periodontal traumatism, occlusal disharmony, functional imbalance and occlusal dystrophy [3].Glossary of Periodontal Terms, define trauma from occlusion as an injury that results in tooth supporting tissue changes as a result of occlusal forces [4].

Trauma from occlusion can be classified as either primary or secondary. Primary trauma from occlusion is described as an abnormal occlusal force acting upon a healthy periodontium. Secondary trauma from occlusion is an occlusal force acting on a reduced or weakened periodontium the force itself may not necessarily be abnormal but excessive for the weakened periodontium [5]. This classification is clarified by the Glossary of Periodontal Terms where primary trauma from occlusion is the Injury resulting in tissue changes from excessive occlusal forces applied to a tooth or teeth with normal support. Secondary trauma from occlusion is when Injury resulting in tissue changes from normal or excessive occlusal forces applied to a tooth or teeth with reduced support [4].

The purpose of Philstrom's study was to evaluate the association between signs of trauma from occlusion, severity of periodontitis and the record of bone support radiographically. The maxillary first molars of 300 individuals were independently evaluated by two examiners for signs of trauma from occlusion, pattern of occlusal contacts and severity of Periodontitis. Each site was also evaluated radiographically by an independent third examiner. The results indicated that: (1) teeth with either bidigital mobility, functional mobility, a widened periodontal ligament space or the 
presence of radiographically visible calculus had deeper probing depth, more loss of clinical attachment and less radiographic osseous support than teeth without these findings, (2) teeth with occlusal contacts in centric relation, working, nonworking or protrusive positions did not exhibit any greater severity of Periodontitis than teeth without these contacts [6].

Glickman and Smulow also examined human autopsy material and agreed that inflammation appeared to begin at the gingival attachment and subsequently progressed into the surrounding periodontal supporting tissue. However, they suggested there was evidence that in teeth undergoing occlusal trauma, the inflammation progressed in a different manner than that in teeth that were not undergoing occlusal trauma. They termed this different progression of periodontal disease as an "altered pathway of destruction." They termed the combined effects of occlusal trauma and inflammation as "co-destructive factors" in periodontal disease [7]. The American Academy of Periodontology (AAP) recently stated that if trauma from occlusion is not treated appropriately in patients with chronic periodontitis, it can lead to progressive bone loss and adverse changes in prognosis and may result in loss of teeth [8].

Some of the more prominent studies of the 1970s and 1980s were performed by two research groups: the University of Gothenburg in Sweden (Lindhe, Ericsson and Nyman) used beagle dogs, while the Eastman Dental Center of Manchester in New York (Polson and Zander) used squirrel monkeys. In these animal models the researchers artificially induced experimental periodontitis by using silk ligatures or byallowing the animals to accumulate plaque and calculus over a variable period of time (usually 6 months). They could then superimpose traumatic occlusion by using cap splints, and evaluate its effect on bone loss and attachment loss. Despite major differences in the animal models and the types of excessive occlusal forces applied, many similar results were obtained from these two studies. The conclusion of both research groups was that without inflammation, occlusal trauma does not cause irreversible bone loss or loss of attachment. Thus, it appears that occlusal trauma in these animals is not a causative agent of periodontal disease [9].

Based on the many opinions that have been put forward by many different researchers, it can be concluded that trauma from occlusion acts as a risk factor that can aggravate tissue damage and periodontitis. The theory and results of these studies have shown a relationship of trauma from occlusion with. However, no detailed research has revealed the role of the relationships of trauma from occlusion with chronic periodontitis based on the quality and quantity of alveolar bone in radiographic features. Therefore, the author feels interested in conducting research on the relationship of trauma from occlusion with chronic periodontitis based on the quality and quantity of alveolar bone in radiographic features.

\section{MATERIALS AND METHODS}

This research is a descriptive analytic research using cross-sectional approach (one time). It is called analytical descriptive research because the research is directed to describe or explain what is the problem, the purpose of research and to find the relationship between variables. While using cross-sectional approach (one time) because the examination, observation or data collection is done at one time (point time approach), meaning that each research respondent is only observed once and the measurement is done to the character's status or the respondent variable at the time of examination.

This research was conducted at the Periodontal Clinic, Faculty of Dentistry USU Medan in May untill Augustus 2017. Population of this research is all patient in Periodontal Clinic, Faculty of Dentistry USU Medan and the sampel from this research are all the patient with chronic periodontitis with secondary trauma from occlusion which meet the criteria of inclusion and exclusion. The sample is determined by using the Accidental Sampling method based on the fact that they happen to appear in order for the purpose.

Criteria for selection were there presence of at least 20 natural teeth, without removable dentures and crossarch bridges, and with no history of periodontal theraphy, occlusal adjustment or orthodontic treatment. None of the patients had any significant systemic disease nor had received any antibiotic theraphy during the previous 3 months also aged 40 to 60 years old according to the subjects with chronic periodontitis patients in this study.

Implementation of the research begins by determining the subject of research and ask the subject to sign the informed concent. Clinical determination of teeth by instructing the patient to bite articulated Ushaped paper placed on the occlusal plain at the centric occlusal position is moved forward (protusively) and laterally. Then, the teeth and tooth surface experiencing the impression were recorded. X-ray of periapical photographs is performed on the patient based on the number of teeth experienced. Later, periodontal ligaments are observed and scores are made, Score 1: There is widening and Score 0: No widening.

Assessments of alveolar bone loss are performed by hand, often using a Schei ruler, with or without magnification, The Schei ruler used was a plastic transparent ruler with a 1-mm-thick marking at its margins and 10 equidistant lines radiating from a center point, each representing $10 \%$ bone loss. According to Schei et al., the 1-mm-thick marking represents the distance between the cemento-enamel junction and the alveolar crest in normal humans with no bone loss. This technique results in the determination of bone loss as a percentage of the original bone level, starting $1 \mathrm{~mm}$ below the cemento-enamel junction, irrespective of the length of the root and its length on the radiograph and irrespective of the direction of the X-ray beams. In the current study, bone loss was determined as the percentage of rootlength. Therefore, the ruler was 
placed on the tooth in question with the 1-mm-thick marking coronal at the tooth radiographic cementoenamel junction and perpendicular at the longitudinal axis of the root (Figure 1). Then, the ruler was moved until the last radius covered the radiographic apex. In the case of lower molar teeth with mesial and distal roots, the apex of the root at the site to be measured was used. In the case of the upper molar teeth, the same root as for the lower molar teeth was used, in fact ignoring the palatal root.The actual amount of bone loss as a percentage of root length was determined by identifying the position of the alveolar crest relative to the ruler's markings. The level of the bone crest was defined as the point along the root where an intact lamina was observed. The actual amounts of bone loss as a percentage of root length could fall into one of 10 categories (Table I). Where no interproximal fillings were present, the cemento-enamel junction could be localized in the vast majority of cases with certainty. In some cases, the cemento-enamel junction was obscured by interproximal fillings. In these cases the cervical margin of the fillings was chosen as a surrogate cemento-enamel junction.

TABLE I. THE ACTUAL AMOUNT OF BONE LOSS AS A PERCENTAGE OF ROOT LENGTH COULD FALL INTO ONE OF 10 CATEGORIES

\begin{tabular}{|c|c|}
\hline Bone loss (percentage of total root length) & Bone loss index \\
\hline$<10$ & 1 \\
\hline 10 to $<20$ & 2 \\
\hline 20 to $<30$ & 3 \\
\hline 30 to $<40$ & 4 \\
\hline 40 to $<50$ & 5 \\
\hline 50 to $<60$ & 6 \\
\hline 60 to $<70$ & 7 \\
\hline 70 to $<80$ & 8 \\
\hline 80 to $<90$ & 9 \\
\hline$\geq 90$ & 10 \\
\hline
\end{tabular}

Next, assess the pattern of alveolar bone destruction: Horizontal or Vertical and the assess condition of the lamina dura by using scores: Score 0: Normal, Score -1: Thickened and Score 1: Discontinue. After that, data collection are processed using computer programs and collected data were analyzed using statistically with chi-square test to see the relationship status of trauma from occlusion with chronic periodontitis based on the quality and quantity of alveolar bone in radiographic features.

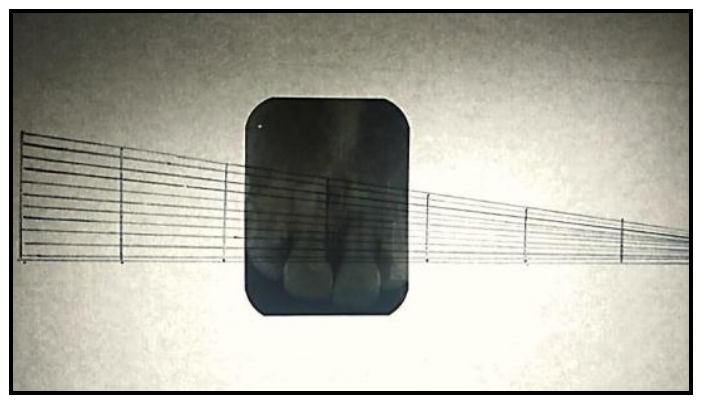

Figure I. Ruler was placed on the tooth in question with the 1-mmthick marking coronal at the tooth radiographic cementoenamel junction and perpendicular at the longitudinal axis of the root.

\section{RESULTS}

The research is conducted at the Periodontal Clinic, Faculty of Dentistry USU Medan in May to Augustus 2017.

TABLE II. FREQUENCY DATA OF TRAUMA FROM OCCLUSION AND NORMAL OCCLUSION

\begin{tabular}{|l|c|c|}
\hline & Total teeth (74) & \% \\
\hline Trauma from Occlusion & 35 & 4.3 \\
\hline Normal Occlusion & 39 & 52.7 \\
\hline
\end{tabular}

Table II shows that there were 35 teeth with trauma from occlusion $(47.3 \%)$ and 39 teeth with normal occlusion $(52,7)$.

TABLE III. RELATIONSHIP OF TRAUMA FROM OCCLUSION AND PERIODONTAL LIGAMENT SPACE (MESIAL AND DISTAL)

\begin{tabular}{|l|lr|r|c|}
\hline \multirow{2}{*}{ Mesial } & \multicolumn{2}{|l|}{ Periodontal Ligament Total Teeth (\%) } & \multirow{2}{*}{ p value } \\
\cline { 2 - 3 } & Trauma from Occlusion & Normal & \\
\cline { 2 - 3 } & Normal & $1(6.2)$ & $15(93.8)$ & \multirow{2}{*}{$0.001^{\mathrm{a}}$} \\
\cline { 2 - 3 } Distal & Widened & $34(58.6)$ & $24(41.4)$ & \\
\cline { 2 - 3 } & Normal & $8(30.8)$ & $18(69.2)$ & \multirow{2}{*}{0.051} \\
\cline { 2 - 3 } & Widened & $27(56.2)$ & $21(43.8)$ & \\
\hline
\end{tabular}

Table III shows the relationship of trauma from occlusion and periodontal ligament space (mesial). Trauma from occlusion with no widened condition has 1 tooth $(6.2 \%)$ is less than normal occlusion of 15 teeth $(93.8 \%)$. Then, the teeth with trauma from occlusion with a widened condition has 34 teeth $(58.6 \%)$ were greater than the normal occlusion of 24 teeth (41.4\%). The results of statistical tests showed that there was a significant relationship between periodontal ligament space and trauma from occlusion with $\mathrm{p}=0.001$ ( $\mathrm{p}$ $<0.005$ ). Table 3 also shows a relationship of trauma from occlusion and periodontal ligament space (distal). Trauma from occlusion with no widened condition has 8 teeth $(30.8 \%)$ is less than the normal occlusion of 18 teeth $(69.2 \%)$. Then, the trauma from occlusion teeth with widened condition of 27 teeth $(56.2 \%)$ greater than the normal occlusion of 21 teeth (43.8\%). The results of statistical tests showed that there was no significant relationship between periodontal ligament space and trauma from occlusion with $\mathrm{p}=0.051(\mathrm{p}<0.005)$.

TABLE IV. RELATIONSHIP OF TRAUMA FROM OCCLUSION AND LAMINA DURA (MESIAL AND DISTAL)

\begin{tabular}{|l|lr|r|c|}
\hline \multirow{2}{*}{$\begin{array}{c}\text { Lamina } \\
\text { dura }\end{array}$} & \multicolumn{3}{|c}{ Total Teeth (\%) } & \multirow{2}{*}{ p value } \\
\cline { 2 - 4 } Mesial & Trauma from Occlusion & Normal & \\
& Thickened & $7(24.1)$ & $22(75.9)$ & \multirow{3}{*}{$0,000^{\mathrm{a}}$} \\
\cline { 2 - 4 } & Normal & $1(16.7)$ & $5(83.3)$ & \\
\cline { 2 - 4 } & Discontinue & $27(69.2)$ & $12(30.8)$ & \\
\hline \multirow{3}{*}{ Distal } & Thickened & $7(35.0)$ & $13(65.0)$ & \multirow{3}{*}{0,082} \\
\cline { 2 - 4 } & Normal & $2(22.2)$ & $7(77.8)$ & \\
\cline { 2 - 4 } & Discontinue & $26(57.8)$ & $19(42.2)$ & \\
\hline
\end{tabular}

Table IV shows the relationship of trauma from occlusion and lamina dura (mesial). Trauma from occlusion with a thickening condition has 7 teeth $(24.1 \%)$ is less than the normal occlusion of 22 teeth $(75.9 \%)$, teeth with trauma from occlusion in normal condition has 1 teeth $(16.7 \%)$ is less than normal 
occlusion of 5 teeth $(83.3 \%)$. Then, the teeth of trauma from occlusion with discontinuous condition were 27 teeth $(69.2 \%)$ greater than the normal occlusion of 12 teeth $(30.8 \%)$. The results of statistical tests showed that there was a significant relationship between lamina dura and trauma from occlusion with $\mathrm{p}=0,000$ ( $\mathrm{p}$ $<0.005)$. Table 4 also shows a relationship of trauma from occlusion and lamina dura (distal). Trauma from occlusion tooth with thickened condition has 7 teeth $(35.0 \%)$ is less than normal occlusion of 13 teeth $(65.0 \%)$, teeth with trauma from occlusion in normal condition is 2 teeth $(22,2 \%)$ less than normal occlusion of 7 teeth $(77.8 \%)$. Then, trauma from occlusion with discontinue condition were 26 teeth $(57.8 \%)$ greater than normal occlusion of 19 teeth $(42.2 \%)$. The result of statistical test showed that there was no significant relationship between lamina dura and trauma from occlusion with $\mathrm{p}=0,082(\mathrm{p}<0,005)$.

TABLE V. RELATIONSHIP OF TRAUMA FROM OCCLUSION AND PATTERN OF ALVEOLAR BONE DESTRUCTION (MESIAL AND DISTAL)

\begin{tabular}{|l|lr|r|c|}
\hline \multirow{2}{*}{ Mesial } & \multicolumn{3}{|c|}{$\begin{array}{c}\text { Pattern of Alveolar Bone Destruction } \\
\text { Total Teeth (\%) }\end{array}$} & \multirow{2}{*}{ p value } \\
\cline { 2 - 4 } & Trauma from Occlusion & Normal & \\
\cline { 2 - 4 } & Vertical & $32(82.1)$ & $7(17.9)$ & \multirow{2}{*}{$0,000^{\mathrm{a}}$} \\
\hline \multirow{2}{*}{ Distal } & Horizontal & $3(8.6)$ & $32(91.4)$ & \\
\cline { 2 - 4 } & Vertical & $31(86.1)$ & $5(13.9)$ & \multirow{2}{*}{$0,000^{\mathrm{a}}$} \\
\hline & Horizontal & $4(10.5)$ & $34(89.5)$ & \\
\hline
\end{tabular}

Table $\mathrm{V}$ shows the relationship of trauma from occlusion and the Pattern of Alveolar Bone Destruction (mesial). Trauma from occlusion teeth with vertical damage were 32 teeth $(82.1 \%)$ were greater than the normal occlusion of 7 teeth $(17.9 \%)$. Then, the trauma from occlusion teeth with horizontal damage as much as 3 teeth $(8.6 \%)$ less than the normal occlusion of 32 teeth $(91.4 \%)$. The result of statistical test shows that there is a significant correlation between the pattern of alveolar bone destruction and trauma from occlusion with $\mathrm{p}=0,000(\mathrm{p}<0,005)$. Table 5 also shows a relationship of trauma from occlusion and the pattern of alveolar bone destruction (distal). Trauma from occlusion with vertical damage of 31 teeth $(86.1 \%)$ were greater than the normal occlusion of 5 teeth $(13.9 \%)$. Then, the trauma from occlusion teeth with horizontal damage of 4 teeth $(10.5 \%)$ were less than the normal occlusion of 34 teeth $(89.5 \%)$. The result of statistical test shows that there is a significant correlation between pattern of alveolar bone destruction and trauma from occlusion with $\mathrm{p}=0,000(\mathrm{p}<0,005)$.

\section{DISCUSSION}

The purpose of this study is to find the relationship of trauma from occlusion with chronic periodontitis based on the quality and quantity of alveolar bone in the radiographic features. The quality of the alveolar bone associated with trauma from occlusion was a visual analysis on the conditions of periodontal ligament, lamina dura and destruction of alveolar bone. The quantity of alveolar bone in associated with trauma from occlusion is performed by measuring the height loss of the alveolar bone by using the schei ruler and light box between the two groups and the samples in the study are patients with chronic periodontitis who are divided into two groups, teeth with trauma from occlusion and teeth with normal occlusion $[10,11]$.

The results of this study indicate that there is a significant relationship between the periodontal ligaments (mesial) and trauma from occlusion where the value of the periodontal ligament that is conditioned as widen is higher in trauma from occlusion group than the normal occlusion group. These results are consistent with Lindhe and Svanberg's research suggesting that in the initial, tissue damage, root resorption and granulation formation in soft tissue occur when subjected to excessive pressure but after a few months, the result is a normal looking periodontium tissue except for the occurrence of widen periodontal ligament space [12]. Philstrom also supports the results of this study where the purpose of this study was to evaluate the association between signs of trauma from occlusion, severity of periodontitis and radiographic record of bone support. The results show that there are teeth with widening of periodontal ligament space on the radiographic image [6].

The results of this study showed no significant relationship between periodontal ligament space (distal) and trauma from occlusion although the periodontal ligament space with widen conditioned in the trauma from occlusion group is higher than normal occlusion group. The results of this study were consistent with Svanberg and Lindhe who conducted the study using 13 beagle dogs in view of vascular reactions in periodontal ligament space and trauma from occlusion. The results of this study were after 108 days of examining the specimens, it was found that the ratio of test area where the widening periodontal ligament space was two or three times greater than the control area [13].

By theory, the injury stage is the stage where excessive pressure stimulates the widening of periodontal ligament space whereas on the other hand excessive stress causes elongation of periodontal ligament fibers.

In the lamina dura condition, the results of statistical tests show that based on the distribution of the number of trauma from occlusion teeth and normal occlusion teeth associated with the lamina dura, there is a significant relationship between lamina dura (mesial) and trauma from occlusion. Whereas, there is no significant relationship between lamina dura (distal) and trauma from occlusion although the lamina dura that is conditioned as loss of continuity is greater than that of the normal occlusion. Jin and Cao supports the results of this study where teeth with thickened lamina dura had less periodontal pockets, less attachment loss and has more osseous support than those with indistinct or disappeared lamina dura [10].

Based on the result of the study, the distribution of trauma from occlusion teeth and normal occlusion teeth when associated withthe pattern of alveolar bone 
destruction has a significant relationship.The vertically pattern of alveolar bone destruction is higher than the horizontal destruction. The results of this study were consistent with Borges which conducted a study on occlusion and periodontal status suggesting that on radiographic results there was vertically alveolar bone destruction between teeth 21 and 11, in mesial tooth 33 and between 31 and 41 and tooth 42 mandibles [14]. Lindhe and Svanberg also support the results of this study. This study used 6 beagle dogs fed soft diets for bacterial plaque formation and after 108 days there was a pattern of alveolar bone damage to the radiographic features where horizontal damage occurred in the control area and test areas and the vertical damage occurred only in the area tested [15].

Glickman conducted the study and found that the pathway extension of gingival lesions associated with plaque may change if there is a large abnormal pressure on the teeth with subgingival plaque. In the irritation zone, the occurrence of gingival inflammation is not due to trauma from occlusion but is the result of irritation of the microbial plaque extending apically by involving the alveolar bone and the periodontal ligament region. The development of these lesions results in equal (horizontal) bone damage. Glickman also states that trauma from occlusion is an important etiologic factor (co-destructive factor) in which the spread of inflammatory lesions from the irritant zone directly leads to a periodontal ligament. The normal pathway changes from plaque-induced inflammatory lesions result in the development of angular (vertical) bone destruction.

Furthermore, statistical tests based on the distribution of the number of trauma from occlusion teeth and normal occlusion teeth associated with the height of bone loss had no significant relation despite the high bone loss of $\geq 50 \%$ in the trauma from occlusion group is higher than the normal occlusion group. The results of this study were supported by Jin and Cao who conducted a study on the clinical signs of trauma from occlusion with the severity of periodontitis. The results showed that there was no significant difference in alveolar bone loss when compared to teeth with or without occlusal contact [10].

In addition, this is also consistent with the results of Philstrom who conducted the study with the aim of evaluating the relationship between signs of trauma from occlusion, severity of periodontitis and bone support by radiographically. The results showed that the non-working teeth showed no greater severity than those with periodontitis and clinically given the same attachment level, the teeth in the presence of functional mobility and widening of the periodontal ligament could be seen to have decreased bone support in radiographic features [6]. Furthermore, Lindhe who conducted the study to see the effects of trauma from occlusion and the periodontal status if the bacterial plaque factor was not included. The study concluded that there was no difference in alveolar bone loss between the 2 control and the test groups [16].
By theory, the stage of injury is the stage where excessive pressure stimulates alveolar bone resorption while on the other hand excessive stress causes alveolar bone apposition.

Based on research conducted at the Periodontal Clinic, Faculty of Dentistry USU Medan can be concluded that there is a relationship of trauma from occlusion with chronic periodontitis based on the quality and quantity of alveolar bone in the radiographic features. The results are as follows: The result of statistical test shows that there is a significant correlation between trauma from occlusion with periodontal ligament space (mesial), lamina dura (mesial) and destruction of alveolar bone (both mesial and distal). The statistical test also showed that there is no significant relationship between trauma from occlusion with periodontal ligament space (distal), lamina dura (distal) and loss of bone height.

\section{REFERENCES}

[1] Y. Gu, M.E. Ryan, Overview of periodontal disease: Causes, pathogenesis, and characteristics. In: R.J. Genco, R.C. Williams, Periodontal disease and overall health: A clinical's guide, USA: Professional Audience Communications Inc., 2010, pp. 5-23.

[2] R.M. Sanadi, L.R. Chelani, S.R. Bhakkand, J.K. Sheth, "Role of trauma from occlusion in periodontal disease-A controversy," IOSR-JDMS., vol. 15(9), pp.118-22, 2016.

[3] S. Reddy, Trauma from occlusion. In: S. Reddy, Essentials of clinical periodontology and periodontitics. $3^{\text {rd }}$ ed., New Delhi: Jaypee Brothers Medical publisher (P) Ltd., 2011, pp. 94-9.

[4] American Academy of Periodontology, Glossary of periodontal terms, $4^{\text {th }}$ ed. Chicago, 2001, pp. 21.

[5] M. Branschofsky, T. Beikler, R. Schafer, T.F. Flemmig, H. Lang, "Secondary trauma from occlusion and periodontitis," Quintessence International, vol. 42(6), pp. 515-22, 2011.

[6] B.L. Philstrom, K.A. Anderson, D. Aepple, E.M. Schaffer, "Association between signs of trauma from occlusion and periodontitis," J. Periodontol., vol. 57(1), pp. 1-6, 1986.

[7] S.K Harrel, M.E. Nunn, W.W. Hallmon, "Is there an association between occlusion and periodontal destruction? yes-occlusal forces can contribute toperiodontal destruction,” J. Am. Dent. Assoc., vol. 137, pp. 1380-92, 2006.

[8] A. Geramy, S. Faghihi, "Secondary trauma from occlusion: Three-dimensional analysis using the finite element method," Quintessence International, vol. 35(10), 835-43, 2004.

[9] G. Consoli, V. Luzzi, G. Lerardo, G.L. Sfasciotti, A. Polimeni, "Occlusal trauma in mixed dentition: literature review," European J. Paediatric Dentistry, vol. 14(1), pp. 47-50, 2013.

[10] L.J. Jin, C.F. Cao, "Clinical diagnosis of trauma from occlusion and its relation with severity of periodontitis," J. Clin. Periodontol., vol. 19, pp. 92-7, 1992.

[11] W.J. Teeuw, L. Coelho, A. Silva, C.J.N.M Palen, U. Velden, B.G. Loos, "Validation of a dental image analyser tool to measure alveolar bone loss in periodontitis patients," J. Periodontal Res., vol. 44, pp. 94-102, 2009.

[12] G. Svanberg, J. Lindhe, "Vascular reactions in the periodontal ligament incident to trauma from occlusion," J. Clin. Periodontol, vol. 1, pp. 58-69, 1974.

[13] J. Lindhe, G. Svanberg, "Influence of trauma from occlusion on progression of experimental periodontitis in the beagle dog," $\mathrm{J}$. Clin. Periodontol., pp. 3-14, 1974.

[14] R.N. Borges, B.M. Arantes, D.F. Vieira, O.A. Guedes, C. Estrela, "Occlusal adjustment in the treatment of secondary traumatic injury," vol. 17(33), pp. 45-50, 2011.

[15] S. Nyman, J. Lindhe, I. Ericsson, "The effect of progressive tooth mobility on destructive periodontitis in the dog," J. Clin Periodontol., vol. 5, pp. 213-25, 1978.

[16] A. Giargia, J. Lindhe, "Tooth mobility and periodontal disease," J. Clin. Periodontol., vol. 24, pp. 785-95, 1997. 